\title{
Angioimmunoblastic T-cell lymphoma with hyperplastic germinal centres: a neoplasia with origin in the outer zone of the germinal centre? Clinicopathological and immunohistochemical study of 10 cases with follicular T-cell markers
}

\author{
Manuel Rodriguez-Justoํㅜ, Ayoma D Attygalle², Phillipa Munson³, Giovanna Roncador ${ }^{4}$,
} Teresa Marafioti ${ }^{5}$ and Miguel A Piris ${ }^{4}$

${ }^{1}$ Department of Histopathology, University College, London, UK; ${ }^{2}$ Department of Histopathology, The Royal Marsden Hospital, London, UK; ${ }^{3}$ UCL Advanced Diagnostics, London, UK; ${ }^{4}$ Lymphoma Group, Molecular Pathology Programme, Spanish National Cancer Research Centre (CNIO), Madrid, Spain and ${ }^{5}$ Leukaemia Research Fund Immunodiagnostics Unit, Nuffield Department of Clinical Laboratory Sciences, University of Oxford, Oxford, UK

\begin{abstract}
Angioimmunoblastic T-cell lymphoma is an aggressive peripheral T-cell lymphoma whose natural history is not fully understood. Up to $17 \%$ of cases can present histologically with hyperplastic germinal centres (pattern I). The accurate recognition of Angioimmunoblastic T-cell lymphoma with pattern I remains a challenge and therefore the aim of this study is to phenotypically and morphologically characterize this variant with the use of the follicular helper T-cell $\left(\mathrm{T}_{\mathrm{FH}}\right)$ markers PD1, CXCL-13 and ICOS. Out of the 88 Angioimmunoblastic T-cell lymphoma cases reviewed, 10 showed hyperplastic follicles. Molecular probe methods for the detection of T-cell and B-cell clonality, as well as in-situ hybridization probes for EBV RNA expression, were carried out to leave no question as to the establishment of the diagnosis in each case. Of the 10 cases, all (100\%) showed strong positive PD1 staining in perifollicular areas and in neoplastic cells surrounding small veins. CXCL13 and ICOS showed a similar staining pattern. By contrast, CD10 was found to only weakly label the neoplastic T cells, with only $5-10 \%$ of the target cell population staining for this marker. EBV was found in $9 / 10$ cases. Clinically, 8/9 cases presented with stage IIIB/IVB and in 2/10 cases consecutive biopsies showed 'progression' from pattern I to classical Angioimmunoblastic T-cell lymphoma. In conclusion we have shown that the $\mathrm{T}_{\mathrm{FH}}$ cells markers PD1, CXCL13 and ICOS are useful adjuncts in the diagnosis of Angioimmunoblastic T-cell lymphoma with hyperplastic germinal centres. PD1 also highlighted the presence of neoplastic cells in the outer zone of lymphoid follicles, suggesting that Angioimmunoblastic T-cell lymphoma (pattern I) may originate from $\mathrm{T}_{\mathrm{FH}}$ cells in this region, in accordance with previous immunological studies. As the majority of cases in our series presented clinically with advanced stage disease, progression from pattern I to classical Angioimmunoblastic T-cell lymphoma may represent histological evolution rather than clinical progression.
\end{abstract}

Modern Pathology (2009) 22, 753-761; doi:10.1038/modpathol.2009.12; published online 27 March 2009

Keywords: Angioimmunoblastic T-cell lymphoma; PD1; ICOS; follicular helper T cell

Angioimmunoblastic T-cell lymphoma is an aggressive peripheral T-cell lymphoma whose natural

Correspondence: Dr M Rodriguez-Justo, FRCPath, Department of Histopathology, University College London Hospitals, Rockefeller Building, 21 University Street, London WC1E 6JJ, UK.

E-mail: m.rodriguez-justo@ucl.ac.uk

Received 28 October 2008; revised and accepted 12 January 2009; published online 27 March 2009 history is not fully understood. It accounts for $1-2 \%$ of all non-Hodgkin's lymphoma. ${ }^{1,2}$ Patients present with generalized lymphadenopathy (up to $90 \%)$, hepatosplenomegaly $(50-79 \%)$, cutaneous rash (50\%), hypergammaglobulinaemia $(50 \%)$, B-symptoms $(70 \%)$, pleural effusion $(37 \%)$ and autoimmune phenomena $(20 \%) .^{3,4}$ More than $75 \%$ of patients are clinical stages III-IV at diagnosis and despite aggressive therapies their median survival is 
less than 3 years. ${ }^{3,5}$ Histologically the majority of cases show regressed follicles, a polymorphous infiltrate of medium-sized lymphocytes with mild cytological atypia, Epstein-Barr virus (EBV)-positive large $\mathrm{B}$ blasts and, characteristically, expanded follicular dendritic cell meshworks encircling high endothelial venules. ${ }^{1}$ However rare cases can present with hyperplastic germinal centres and this pattern has been frequently misdiagnosed as reactive hyperplasia. ${ }^{3,6}$ The natural history and frequency of these cases, also known as pattern I, is poorly documented with only small series and a few case reports. ${ }^{7-10}$ It remains to be determined whether patients with angioimmunoblastic T-cell lymphoma -(pattern I) have a similar or different clinical presentation and behaviour to classical angioimmunoblastic T-cell lymphoma. Furthermore little is known of the histologic progression of angioimmunoblastic T-cell lymphoma in consecutive biopsies and whether this progression has any clinical significance.

Recent gene-expression profiling studies have suggested that $\mathrm{T}_{\mathrm{FH}}$ (follicular helper $\mathrm{T}$ cells) may be the cell of origin of Angioimmunoblastic T-cell lymphoma. ${ }^{11,12} \mathrm{~T}_{\mathrm{FH}}$ cells are CXCR5 +/CCR7- T cells, located in germinal centres, which provide help to B cells in cellular immune responses, through the acquisition of other molecules such as ICOS (immune costimulatory molecule), CD40L and IL-21. ${ }^{13}$ Among the genes upregulated in $\mathrm{T}_{\mathrm{FH}}$ cells are CXCL13, BCL6 and programmed death-1 (PD1) ${ }^{14}$ and these molecules can be detected by immunohistological staining of paraffin sections. PD1 and CXCL13 are particularly useful markers in the diagnosis of Angioimmunoblastic T-cell lymphoma, helping to differentiate this condition from lymphoid hyperplasias and peripheral T-cell lymphoma unspecified (PTCL-u). ${ }^{15-20}$

Animal studies have shown that germinal centres have three compartments: the dark zone, the light zone and the 'outer zone', the latter being rich in CD4 ${ }^{+}$CXCR5 $^{+}$CD57 $^{-} \mathrm{T}_{\mathrm{FH}}$ cells. ${ }^{21}$ In addition $\mathrm{T}_{\mathrm{FH}}$ appear to express high levels of the 'inducible costimulatory' (ICOS) molecule, a CD28 homologue implicated in the regulation of T-cell differentiation. It has recently been proposed that ICOS may be dysregulated in angioimmunoblastic T-cell lymphomas. ${ }^{22}$ Preliminary studies with ICOS in paraffin sections have shown a similar staining pattern to PD1. The majority of ICOS $+\mathrm{T}$ cells also express PD1 and Bcl6. Angioimmunoblastic T-cell lymphoma (51/52) and 18/18 follicular variant of peripheral T-cell lymphoma have also been shown to be positive with ICOS (Marafioti T (2008), manuscript in preparation).

In view of the difficulty in distinguishing Angioimmunoblastic T-cell lymphoma with hyperplastic germinal centres (pattern I) from reactive follicular hyperplasias on morphological criteria alone, we undertook this study with the aim of analysing the expression of $\mathrm{T}_{\mathrm{FH}}$ markers (PD1,
CXCL13 and ICOS) in 10 cases of Angioimmunoblastic T-cell lymphoma pattern I. Morphological, immunohistochemical and clinical features of this Angioimmunoblastic T-cell lymphoma subgroup were also analysed.

\section{Materials and methods}

\section{Tissue Samples}

We reviewed a group of 88 consecutive nodal Angioimmunoblastic T-cell lymphoma cases submitted for diagnosis or second opinion to University College London Hospital and the Spanish National Cancer Institute (CNIO, Pathology Laboratory) between 1998 and 2007. Ten cases were classified as Angioimmunoblastic T-cell lymphoma (pattern I)/ hyperplastic germinal centres. Criteria for the diagnosis were based on WHO recommendations ${ }^{1}$ and previous studies, ${ }^{7,9}$ including hyperplastic follicles, a polymorphous infiltrate composed of medium-sized lymphocytes, transformed large blasts, plasma cells, macrophages and eosinophils, associated with prominent vascularity in the paracortex and/or a subtle expansion of the follicular dentritic cell meshwork. Twenty-one ${ }^{21}$ lymph nodes with reactive follicular hyperplasia (including four cases of HIV associated lymphadenopathy) were included as controls and the staining pattern of CXCL13, PD1 and ICOS was examined in both the reactive nodes and Angioimmunoblastic T-cell lymphoma pattern I cases. The use of archival tissues was approved by the local research ethics committees of the authors' institutions.

\section{Immunohistochemistry}

Immunohistochemical staining of tissue sections was performed using the EnVision staining system ${ }^{23}$ with a heat-induced antigen-retrieval step. Sections were immersed in boiling $10 \mathrm{mM}$ sodium citrate at pH 6.5 for 2 min in a pressure cooker. Each case was stained with a panel of 11 different antibodies (Table 1) including the new, but well-recognized

Table 1 Antibodies

\begin{tabular}{lllc}
\hline Antibody & Clone & Source & Dilution \\
\hline CD3 & SP7 & Neomarkers & $1: 200$ \\
CD4 & 4B12 & Master Diagnostica & $1: 3$ \\
CD8 & C8/133B & Dako & $1: 25$ \\
CD30 & COGD/B9 & Ac Monoclonal & $1: 1$ \\
PD-1 & NAT-105 & Monoclonal Ab CNIO & $1: 2$ \\
CD10 & 56C6 & Novocastra & $1: 10$ \\
CD21 & IF8 & Dako & $1: 10$ \\
CD23 & MHM6 & Dako & $1: 25$ \\
CXCL-13 & Mouse poly & R\&D Systems & $1: 25$ \\
ICOS & T Marafioti & T Marafioti & T Marafioti \\
LMP-1 & CS.1-4 & Dako & $1: 2000$ \\
\hline
\end{tabular}


$\mathrm{T}_{\mathrm{FH}}$ cell markers such as CXCL-13, PD1 and ICOS. Reactive tonsil was used as control. The primary antibodies were omitted to provide negative controls. For CXCL-13, PD1 and ICOS expression, the percentage of neoplastic cells was scored as follows: -, no evidence of positivity; +, 5-15\% positive neoplastic cells;,$++ 15-40 \%$ positive neoplastic cells and +++ , more than $40 \%$ positive neoplastic cells.

\section{In Situ Hybiridization for EBV-Encoded RNA}

The presence of EBV RNA was analysed by nonisotopic in situ hybridization with EBV-encoded RNA (EBER) 1 and 2 oligonucleotide probes (Dakocytomation) on paraffin-embedded tissue sections, as previously described. ${ }^{24}$

\section{B-Cell and T-Cell Clonality Studies}

Polymerase chain reaction (PCR) was performed to analyse the clonal expansion of T and B cells. DNA was extracted from paraffin sections and T-cell clonal expansion was detected by analysis of T-cell receptor $(\mathrm{TCR})_{\beta} \quad\left(\mathrm{V}_{\beta} \mathrm{J}_{\beta}\right.$ and $\left.\mathrm{D}_{\beta} \mathrm{J}_{\beta}\right)$ and $\mathrm{TCR}_{\gamma}$ gene rearrangement, as previously described. ${ }^{25}$ B-cell clonal expansion was detected by PCR for the immunoglobulin heavy $\left(\mathrm{IgH}, \mathrm{V}_{\mathrm{H}^{-}} \mathrm{J}_{\mathrm{H}}\right.$ and $\left.\mathrm{D}_{\mathrm{H}^{-}} \mathrm{J}_{\mathrm{H}}\right)$ chain rearrangement. Appropriate positive and negative controls were included in all experiments.

\section{Results}

\section{Clinical Features}

Clinical details are summarized in Table 2. There were seven men and three women who were between the ages of 34 and 105 years at presentation. Eight of nine cases (where staging information was available) presented with disseminated disease (stages III-IV). Extranodal involvement was present in 6 patients $(66.7 \%)$, most frequently lung, bone marrow, liver, skin and central nervous system, in $22 \%$ (2/9), $22 \%$ (2/9), $11 \%$ (1/9), $11 \%(1 / 9)$ and $11 \%$ (1/9). Organomegaly (hepato or splenomegaly) was present in three patients (33\%), three patients (33\%) had haemolytic autoimmune anaemia and one patient $(11 \%)$ had polyclonal gammapathy. The International Prognostic Index (IPI) was recorded in seven patients: five $(71 \%)$ patients were classified as low risk (0-1) and two $(29 \%)$ as intermediatehigh risk (IPI 3). Follow-up was available in nine cases and after a median follow-up of 37 months (range 16-68 months) seven patients (78\%) were still alive and four (44\%) achieved complete remission with no evidence of recurrent disease. Two patients $(22 \%)$ died of the disease.

\section{Histology, Immunohistochemistry and Molecular Studies (Table 3)}

Histologically, all 10 cases showed hyperplastic germinal centres with a few tingible-body macrophages and indistinct mantle zones. There was expansion of the interfollicular area by a polymorphic infiltrate composed of medium-sized lymphocytes, immunoblasts, plasma cells, eosinophils and high-endothelial postcapillary venules. Scattered clusters of clear cells were seen in three cases. In eight cases, there was a subtle expansion of follicular dendritic cells (FDC) highlighted with CD21/23 but no large accumulations of FDC encircling high-endothelial veins were detected.

All 10 cases were positive for both PD1 (membrane) and CXCL13 (cytoplasmic and sometimes dot-like reinforcement) markers but the percentage and strength of staining of positive cells was more intense with PD1 than CXCL13. Interestingly, PD1 showed a strong 'perifollicular' pattern with aggregates of positive cells in the outer zone of the germinal centre and also highlighted clusters of neoplastic cells around high endothelial venules. Eight cases stained with ICOS showed similar strong perifollicular pattern and also demonstrated clusters of neoplastic cells in interfollicular areas (Figure 1).

Neoplastic cells were CD3 + /CD4 + /CD8- in 10/ 10 cases $(100 \%)$. CD10 + cells typically accounted for $5-10 \%$ of CD3 + cells and represented a smaller subset of CD3 + cells than PD1 + cells $(>40 \%$ of neoplastic cells in $60 \%$ of cases). EBER + B-blasts were present in $9 / 9$ cases $(100 \%)$.

In reactive follicular hyperplasias PD1, CXCL13 and ICOS were expressed by a few cells in germinal centres and a few $\mathrm{T}$ cells in interfollicular areas (weak staining; Figure 2) but no other morphological

Table 2 Clinical data

\begin{tabular}{lc}
\hline Clinical data & $9 / 10(90 \%)$ \\
Median age at diagnosis & 66 years $(34-105)$ \\
Sex & 7 males/3 females \\
Stage III-IV & $8 / 9(89 \%)$ \\
& \\
IPI & $5 / 7(71 \%)$ \\
$\quad$ Low & $2 / 7(29 \%)$ \\
Intermediate/high & \\
& $6 / 9(67 \%)$ \\
Extranodal involvement & $2 / 9(22 \%)$ \\
Lung & $2 / 9(11 \%)$ \\
Bone marrow & $1 / 9(11 \%)$ \\
Liver & $1 / 9(11 \%)$ \\
Skin & $1 / 9(11 \%)$ \\
CNS & $1 / 9(11 \%)$ \\
Serous (pleural) & $2 / 9(22 \%)$ \\
Organomegaly & $3 / 9(33 \%)$ \\
Autoimmune phenomena & $1 / 9(11 \%)$ \\
Polyclonal gammapathy & Median $37 \mathrm{months}$ \\
Follow up & $(18-68)$ \\
& $7 / 9(78 \%)$ \\
Alive & $4 / 9(44 \%)$ \\
Complete remission &
\end{tabular}


Table 3 Immunohistochemistry and molecular studies

\begin{tabular}{|c|c|c|c|c|c|c|c|c|c|c|c|c|c|c|c|}
\hline Case & Sex/age & Site & Progression & CD3 & $C D 4$ & $C D 8$ & CD30 & $C D 23 / 21$ & CD10 & $E B V$ & $\operatorname{IgH}$ & TCR & $C X C L 13^{\mathrm{a}}$ & $P D 1^{\mathrm{a}}$ & $I_{C O S}^{\mathrm{a}}$ \\
\hline 1 & oิ 72 & $\mathrm{LN}$ & $\mathrm{n} / \mathrm{a}$ & + & + & - & ND & $\uparrow \mathrm{FDC}$ & $10 \%$ CD3 & + & ND & Mono & + & ++ & ++ \\
\hline 2 & † 41 & $\mathrm{LN}$ & $\mathrm{I} \rightarrow \mathrm{II}$ & + & + & - & ND & No $\uparrow$ FDC & ND & + & ND & Mono & + & +++ & +++ \\
\hline 3 & o 34 & LN & $\mathrm{n} / \mathrm{a}$ & + & + & - & ND & $\uparrow$ FDC & - & + & Poly & Poly & + & ++ & ++ \\
\hline 4 & ㅇ 105 & $\mathrm{LN}$ & $\mathrm{n} / \mathrm{a}$ & + & + & - & + & $\uparrow$ FDC & ND & + & Poor DNA & Poor DNA & + & ++ & + \\
\hline 5 & o 65 & LN & $\mathrm{I} \rightarrow \mathrm{II}$ & + & + & - & + & $\uparrow \mathrm{FDC}$ & 10\% CD3 & + & Poly & Oligo & + & + & ND \\
\hline 6 & ô 80 & $\mathrm{LN}$ & $\mathrm{n} / \mathrm{a}$ & + & + & - & ND & $\uparrow$ FDC & $10 \%$ CD3 & ND & Poor DNA & Poor DNA & + & +++ & ++ \\
\hline 7 & 67 & $\mathrm{LN}$ & $\mathrm{n} / \mathrm{a}$ & + & + & - & ND & n/a & $5 \%$ CD3 & + & Mono & Oligo & ++ & +++ & ND \\
\hline 8 & o 59 & $\mathrm{LN}$ & $\mathrm{n} / \mathrm{a}$ & + & + & - & ND & $\uparrow$ FDC & $5 \%$ CD3 & + & ND & ND & ++ & +++ & ++ \\
\hline 9 & ô 73 & $\mathrm{LN}$ & $\mathrm{n} / \mathrm{a}$ & + & + & - & + & $\uparrow$ FDC & $10 \%$ CD3 & + & ND & ND & + & +++ & ++ \\
\hline 10 & ๙ 65 & $\mathrm{LN}$ & $\mathrm{n} / \mathrm{a}$ & + & + & - & ND & $\uparrow \mathrm{FDC}$ & ND & + & ND & ND & ++ & +++ & ++ \\
\hline
\end{tabular}

ND: not done; n/a: not available, LN: lymph node, $\uparrow$ FDC: mild expansion follicular dendritic cell meshwork; Mono: monoclonal band; Poly: polyclonal band, Oligo: oligoclonal.

${ }^{a}$ CXCL-13, PD-1 and ICOS expression: -, no evidence of positivity; +, 5-15\% positive neoplastic cells; ++, 15-40\% positive neoplastic cells; +++, more than $40 \%$ positive neoplastic cells.

features of Angioimmunoblastic T-cell lymphoma were present in these cases.

PCR studies of both IgH and TCR gene rearrangement were informative in three and five cases, respectively. IgH clonal rearrangement was present in one case (case 7) and monoclonal TCR rearrangement was detected in two patients (cases 1 and 2).

In two patients, whose initial biopsy showed Angioimmunoblastic T-cell lymphoma (pattern I) (cases 2 and 5), consecutive biopsies (11 and 24 months after initial diagnosis) showed typical features of Angioimmunoblastic T-cell lymphoma (pattern II) with a polymorphic infiltrate, expanded meshwork of FDC surrounding vessels and prominent high endothelial venules. PD1 in these two cases highlighted increased number of neoplastic cells distributed around expanded FDC meshworks (Figure 3).

\section{Discussion}

The diagnostic criteria for Angioimmunoblastic T-cell lymphoma, as defined by Dogan et al, ${ }^{1}$ only apply to typical (pattern II/III) cases but in a significant proportion of cases (up to $17 \%)^{3,26}$ the morphological findings mimic reactive follicular hyperplasia. The histological architecture of Angioimmunoblastic T-cell lymphoma with pattern I is characterized by largely preserved lymph node architecture, hyperplastic B-cell follicles surrounded by expanded paracortex containing a polymorphic infiltrate of lymphocytes, transformed large lymphoid blasts, plasma cells, macrophages and eosinophils with a prominent vascular network and little or no evidence of follicular dendritic cells expansion. ${ }^{6}$ Early reports suggested that germinal centres with irregular borders and abundant tingible body macrophages in interfollicular areas were characteristic of pattern I Angioimmunoblastic T-cell lymphoma ${ }^{9}$ but these criteria are not repro- ducible and a correct diagnosis cannot always be achieved based on morphological findings alone.

Our data corroborate previous studies ${ }^{18}$ showing that expression of PD1 and CXLC13 in non-neoplastic lymph nodes and reactive follicular hyperplasias is confined to a few T cells in germinal centres and scattered $\mathrm{T}$ cells in interfollicular areas (usually weak). In addition we have shown that in pattern I Angioimmunoblastic T-cell lymphoma, $\mathrm{T}_{\mathrm{FH}}$ cell markers, particularly PD1, highlight clusters of neoplastic cells in 'perifollicular' areas and around high endothelial venules in the expanded paracortex. This 'perifollicular' pattern of neoplastic cells was also recorded in $3 / 29$ cases reported by Dupuis et $a^{17}$ with CXCL13 antibody staining. In our experience, the presence and pattern of distribution of PD1 + T cells and EBER + B blasts (90\% in our series) is very helpful in distinguishing Angioimmunoblastic T-cell lymphoma pattern I from reactive hyperplasias. We have shown that PD1 has a diagnostic utility in the diagnosis of Angioimmunoblastic T-cell lymphoma, but it should be pointed out that expression of PD1 has also been reported in a small group of PTCL-u, diffuse large B-cell lymphomas ${ }^{18}$ and very recently in small lymphocytic lymphoma (SLL) and grade III follicular lymphoma. ${ }^{27}$

Our results are in accordance with preliminary results by Marafioti-T (data presented at the Groupe d'Etudes des Lymphomes de l'Adulte (GELA) meeting 2008, manuscript in preparation), showing that ICOS is a useful marker in the diagnosis of Angioimmunoblastic T-cell lymphoma and provides further evidence to support the derivation of Angioimmunoblastic T-cell lymphoma from $\mathrm{T}_{\mathrm{FH}}$ cells.

Although CD10 has been proposed as an immunophenotypic marker of neoplastic $\mathrm{T}$ cells in Angioimmunoblastic T-cell lymphoma in up to $90 \%$ of cases, ${ }^{6}$ we found that only a small proportion of neoplastic T cells (5-10\%) expressed CD10 whereas the proportion of neoplastic PD1 + cells was $>40 \%$ in $6 / 10$ cases $(60 \%$ in this study). 

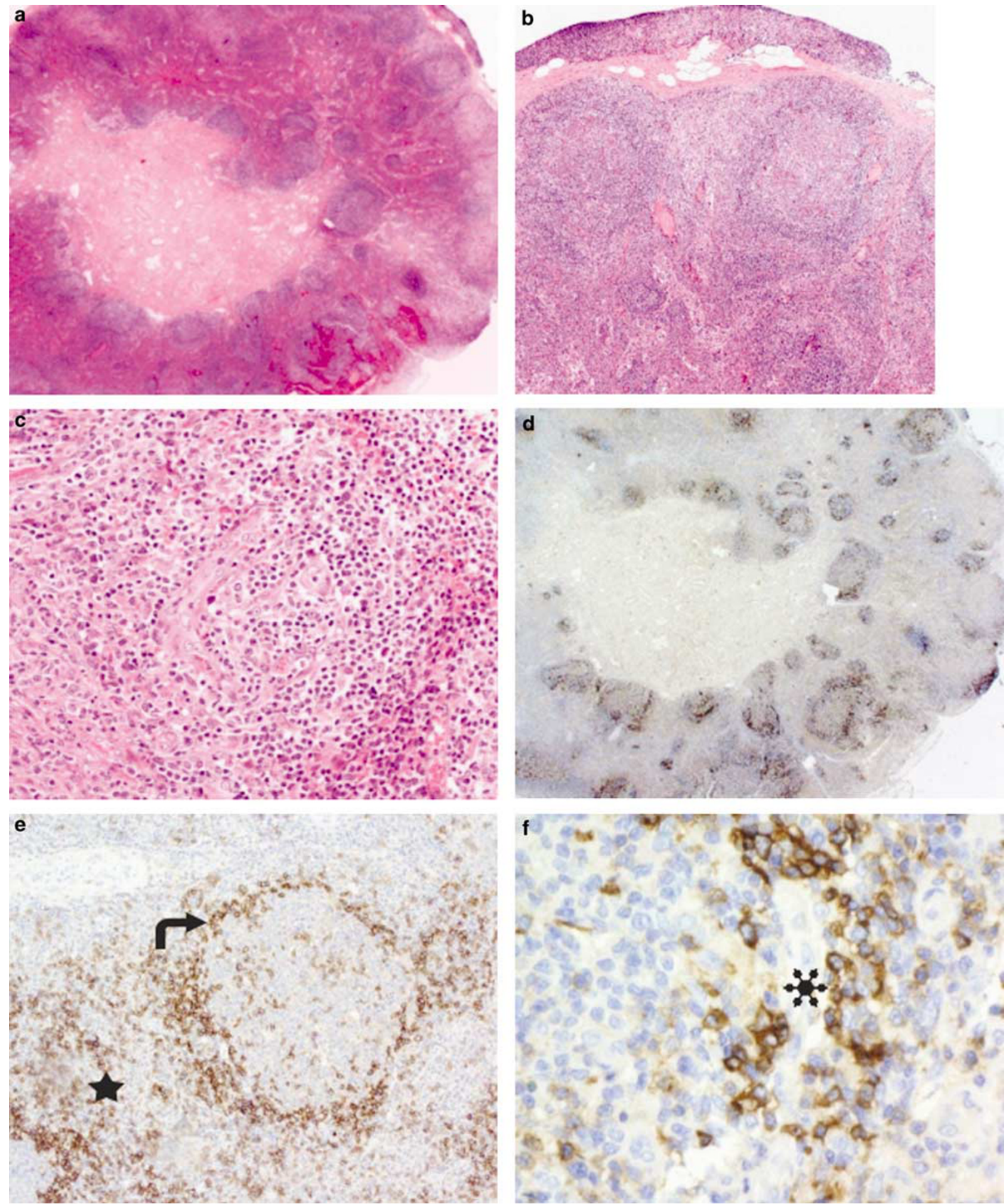

Figure 1 Initial biopsy of case no. 5 showing Angioimmunoblastic T-cell lymphoma pattern I. (a-c) Hematoxylin and eosin (H\&E)stained sections showing hyperplastic follicles $(\times 4)$, ill-defined mantle zone $(\times 20)$ and perivascular aggregates of neoplastic cells $(\times 20)$. (d, e) PD1 staining with typical "perifollicular" pattern (arrow) and sheets of atypical cells outside the follicle (asterisk). (f) PD1 stain in a cluster of lymphoid cells surrounding a small vein (asterisk).

Chandra et $a l^{28}$ and Dorfman et $a l^{16}$ have also demonstrated the superior diagnostic utility of PD1 and CLX13 when compared to CD10 and Bcl-6.
The compartimentalization of the germinal centre, function and immunophenotype of $\mathrm{T}_{\mathrm{FH}}$ cells has been unknown until recently. Initial studies by 

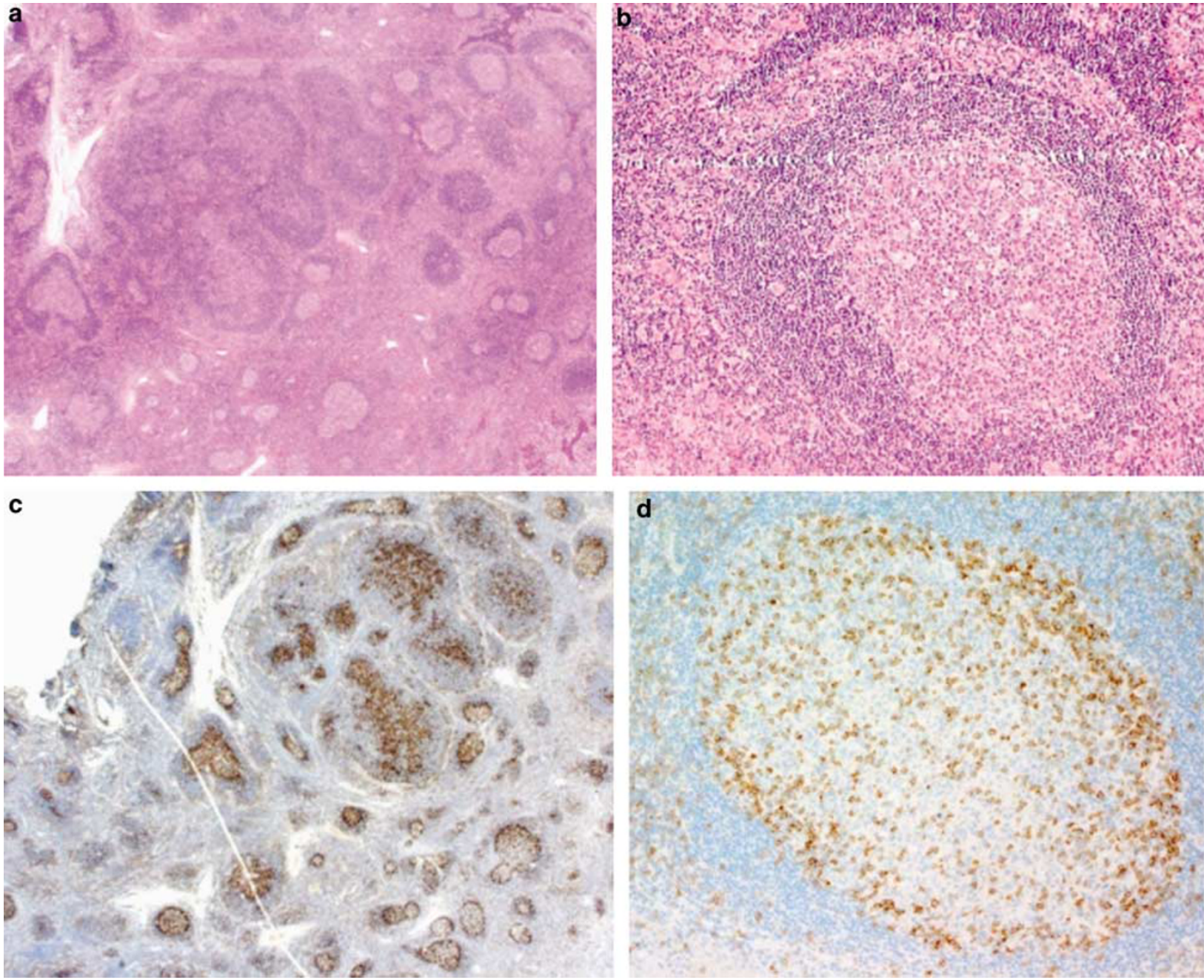

Figure $2 \mathrm{~T}_{\mathrm{FH}}$ cell markers in reactive lymphoid hyperplasia. (a, b) Hyperplastic follicles with reactive germinal centres and well-defined mantle zones (H\&E $\times 4$ and $\times 20$, respectively). Immunoperoxidase staining for PD1 (c, low magnification) and ICOS (d, higher magnification).

Hardie et $a l^{29}$ define five compartments in the follicle based on immunofluorescence techniques: follicular mantle, outer zone, apical light zone, basal light zone and dark zone. Using the 'sanroque' mouse (deficient in the ICOS repressor Roquin), Vinuesa et $a l^{21}$ have shown that $\mathrm{T}_{\mathrm{FH}}$ cells are genotypically and phenotypically different from $\mathrm{T}_{\mathrm{H}} 1$ and $\mathrm{T}_{\mathrm{H}} 2$ cells and express ICOS, CXCR5, PD1, CXCL13 and interleukin-21 (IL-21). Interestingly it has been suggested that the production of IL-21 by $\mathrm{T}_{\mathrm{FH}}$ cells is responsible for the B-cell activation and hypergammaglobulinemia seen in Angioimmunoblastic T-cell lymphoma. ${ }^{13}$ Vinuesa's group ${ }^{21}$ has identified different subsets of $\mathrm{T}_{\mathrm{FH}}$ cells in different locations in the germinal centre; one subset, located in the outer zone of the germinal centre, shares the immunophenotype of the neoplastic cells in Angioimmunoblastic T-cell lymphoma. The 'outer zone' may correspond to the 'perifollicular' location of neoplastic PD1 + cells in pattern I and it is possible that Angioimmunoblastic T-cell lymphoma originates in the outer zone of the germinal centre.

It remains to be determined whether patients with Angioimmunoblastic T-cell lymphoma pattern I have a similar or different clinical presentation and behaviour compared to classical cases and if there is a histologic progression of pattern I to classical Angioimmunoblastic T-cell lymphoma (II and III) in consecutive biopsies. Attygalle et $a l^{7}$ reported seven cases of pattern I Angioimmunoblastic T-cell lymphoma on initial biopsies and 'typical' patterns II/III on follow-up biopsies. Two out of seven cases reported by Ree et $a l^{9}$ also progressed to typical Angioimmunoblastic T-cell lymphoma and in our series two patients, at 11 and 24 months interval, showed pattern II on follow-up biopsies. However relapse of Angioimmunoblastic T-cell lymphoma with morphological features of 


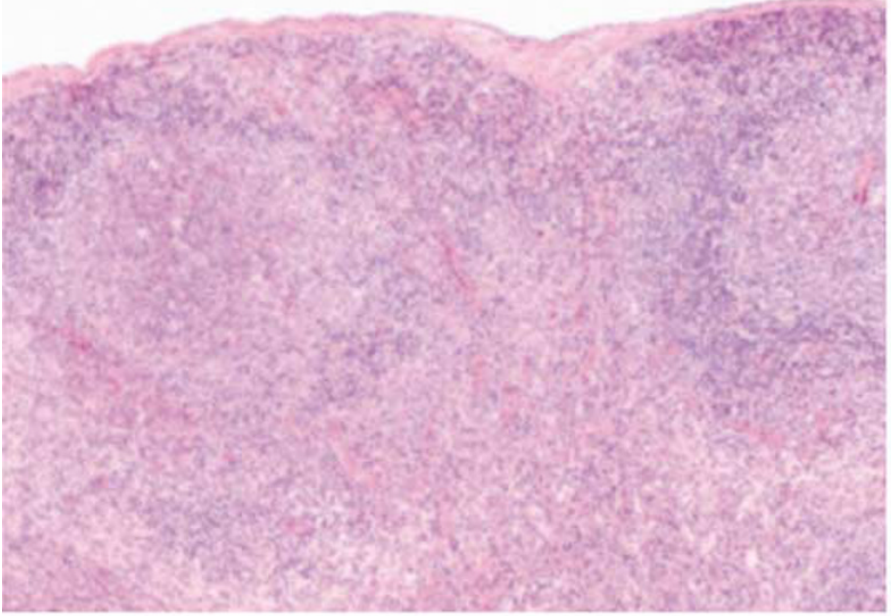

b
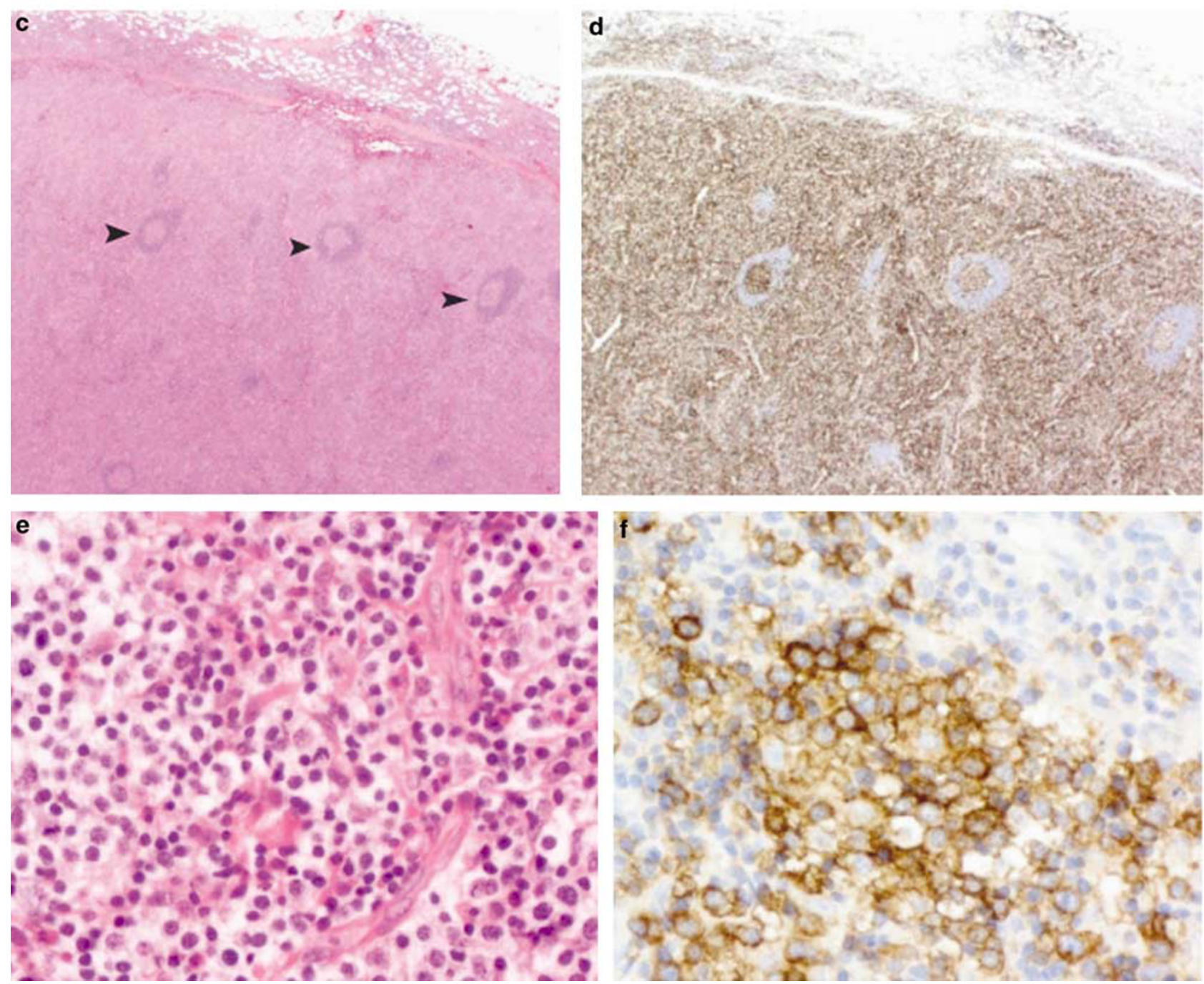

Figure 3 Initial and follow-up biopsies (at 11 months) from case no. 2 showing progression from pattern I to classical Angioimmunoblastic T-cell lymphoma. (a) H\&E section on initial biopsy showing hyperplastic follicles and expansion of the interfollicular paracortical area $(\times 10)$. (b) PD1 staining on initial biopsy highlighting the "perifollicular" pattern (arrow) $(\times 20)$. $(\mathbf{c}-\mathbf{f})$ Follow-up biopsy with typical Angioimmunoblastic T-cell lymphoma (pattern II). H\&E section showing effacement of the lymph node architecture with a few atrophic follicles (arrows) (H\&E $\times 4$ ). Immunoperoxidase stain for PD1 on follow-up biopsy (d). Sheets of clear cells in follow-up biopsy stained with H\&E (e) and ICOS (f). 
Table 4 Progression from pattern I to pattern II/III

\begin{tabular}{lll}
\hline & Staging at diagnosis & Progression to pattern II/III \\
\hline Ree et al (1998) & $5 / 7$ stage III/IV & $2 / 7$ (interval 1-7 months) \\
Kokima et al (2001) & $8 / 10$ stage III/IV & $4 / 10$ (?interval) \\
Attygalle et al (2007) & $2 / 3$ stage IVB & $3 / 3$ (interval 2-23 months) \\
Rodriguez-Justo et al (CNIO and UCLH) & $8 / 9$ stage III/IV & $2 / 10$ (interval 11-24 months)
\end{tabular}

hyperplastic germinal centres has also been seen after complete remission. ${ }^{7}$ Interestingly, despite early involvement (pattern I) histologically, the majority of patients in all published series (Table 4) presented with clinical stages III/IV. All these findings suggest that progression from pattern I to II/ III is a histological evolution rather than a truly clinical progression of the disease as the majority of the patients had clinically advanced disease at diagnosis. It might also be possible that pattern I represents a variable degree of involvement of different lymph nodes at one time (ie limited involvement in pattern I vs more extensive in patterns II/III). Zhou et $a l^{30}$ have shown an association among EBV, human herpesvirus (HHV) 6 and histological progression of Angioimmunoblastic T-cell lymphoma. EBV and HHV6 may play a role in the pathogenesis of this type of lymphoma and this might explain why some patients with Angioimmunoblastic T-cell lymphoma respond to antiviral therapy with valacyclovir. ${ }^{31}$

Finally, some cases described as peripheral T-cell lymphomas with follicular pattern ${ }^{32}$ characterized by a follicular/perifollicular pattern and $\mathrm{CD}^{+}$ $\mathrm{CD}^{-} \mathrm{CD}^{-} 7^{-} \mathrm{Bcl6}^{+} \mathrm{CD}^{+} 0^{+}$immunophenotype might represent Angioimmunoblastic T-cell lymphoma pattern I. Recent studies using $\mathrm{T}_{\mathrm{FH}}$ cells markers have shown that a proportion of these cases derive from $\mathrm{T}_{\mathrm{FH}}$ cells and might be related to angioimmunoblastic T-cell lymphomas. ${ }^{20,33}$ Although the relationship between Angioimmunoblastic T-cell lymphoma and follicular PTCL-u merits further investigation, follicular PTCL remains as a variant of 'PTCL not otherwise specified' in the current WHO Lymphoma classification. ${ }^{34}$

In summary, we have presented the clinical, morphological and immunophenotypical features of 10 cases of Angioimmunoblastic T-cell lymphoma using $\mathrm{T}_{\mathrm{FH}}$ cells markers in which current immunological studies and the presence of 'perifollicular' clusters of neoplastic cells raise the possibility that this tumour originates in the outer zone of the germinal centre. Our results also highlight the need to revise existing pathological criteria that are used to define Angioimmunoblastic T-cell lymphoma as the spectrum of this lymphoma may be broader than previously recognized and should include the recognition of the variant with hyperplastic germinal centres.

\section{Acknowledgement}

We thank the Tumour Bank Group (Spanish National Cancer Institute, CNIO), Maria Encarnacion Castillo-Sanchez and Laura Cereceda (Lymphoma Group, CNIO) and Sue Goddard (UCLH) for their assistance and support.

\section{Disclosure/conflict of interests}

The authors declared no conflict of interest.

\section{References}

1 Dogan A, Gaulard P, Jaffe ES, et al. Angioimmunoblastc T-cell lymphoma. In: Swerdlow SH, Campo E, Harris NL et al. (eds). Pathology and Genetics of Tumours of Haematopoietic and Lymphoid Tissues. World Health Organization Classification of Tumours, 4th edn. IARC press: Lyon, 2008, pp 309-311.

2 Rudiger T, Weisenburger DD, Anderson JR, et al. Peripheral T-cell lymphoma (excluding anaplastic large-cell lymphoma): results from the Non-Hogkin's Lymphoma Classification. Ann Oncol 2002;13: 140-149.

3 Lachenal F, Berger F, Ghesquerides H, et al. Angioimmunoblastic T-cell lymphoma. Clinical and laboratory features at diagnosis in 77 patients. Medicine 2007;86:282-292.

4 Iannitto E, Ferrari AJM, Minardi V, et al. Angioimmunoblastic T-cell lymphoma. Crit Rev Oncol Hematol 2008;68:264-271.

5 Pellatt J, Sweetenham J, Pickering RM, et al. A singlecentre study of treatment outcomes and survival in 120 patients with peripheral T-cell non-Hodgkin's lymphoma. Ann Hematol 2002;81:267-272.

6 Attygalle AD, Al-Jehani R, Diss TC, et al. Neoplastic T cells in angioimmunoblastic T-cell lymphoma express CD10. Blood 2002;99:627-633.

7 Attygalle AD, Kyriakou C, Dupuis J, et al. Histologic evolution of angioimmunoblastic T-cell lymphoma in consecutive biopsies: clinical correlation and insights into natural history and disease progression. Am J Surg Pathol 2007;31:1077-1088.

8 Kojima M, Nakamura S, Itoh $\mathrm{H}$, et al. Angioimmunoblastic T-cell lymphoma with hyperplastic germinal centres: a clinicopathological and immunohistochemical study of 10 cases. APMIS 2001;109:699-706.

9 Ree HJ, Kadin ME, Kikuchi M, et al. Angioimmunoblastic T-cell lymphoma with hyperplastic germinal centres. Am J Surg Pathol 1998;22:643-655. 
10 Merchant SH, Amin MB, Wiswanatha DS. Morphologic and immunophenotypic analysis of angioimmunoblastic T-cell lymphoma. Emphasis on phenotypic aberrancies for early diagnosis. Am J Clin Pathol 2006;126:29-38.

11 Piccaluga PP, Agostinelli C, Califano A, et al. Gene expression analysis of angioimmunoblastic T-cell lymphoma indicates derivation from T-follicular helper cells and vascular endothelial growth factor deregulation. Cancer Res 2007;67:10703-10710.

12 de Leval L, Rickman DS, Thielen C, et al. The gene expression profile of nodal peripheral T-cell lymphoma demostrates a molecular link between angioimmunoblastic T-cell lymphoma and follicular helper T-cells. Blood 2007;109:4952-4963.

13 King C, Tangye SG, Mackay CR. T- Follicular Helper cells in normal and dysregulated immune responses. Ann Rev Immunol 2008;26:741-766.

$14 \mathrm{Kim} \mathrm{CH}$, Lim HW, Kim JR, et al. Unique gene expression program of human germinal center T helper cells. Blood 2004;104:1952-1960.

15 Crogg KL, Attygalle AD, Macon WR, et al. Expression of CXCL13, a chemokine highly upregulated in germinal center T-helper cells, distinguishes AIT from PTCL-u. Mod Pathol 2006;19:1101-1107.

16 Dorfman DM, Brown JA, Shahsafaei A, et al. PD-1 is a marker of germinal center-associated T-cells and angioimmunoblastic T-cell lymphoma. Am J Surg Pathol 2006;30:802-810.

17 Dupuis J, Boye K, Martin N, et al. Expression of CXCL13 by neoplastic cells in angioimmunoblastic T-cell lymphoma: a new diagnostic marker providing evidence that angioimmunoblastic T-cell lymphoma derives from follicular helper T cells. Am J Surg Pathol 2006;4:490-494.

18 Roncador G, Garcia Verdes-Montenegro JF, Tedoldi S, et al. Expression of two markers of germinal center Tcells (SAP and PD-1) in angioimmunoblastic T-cell lymphoma. Haematologica 2007;92:1059-1066.

19 Montes-Moreno S, Rodriguez-Pinilla SM, Atienza L, et al. PD-1 expression helps to differentiate cutaneous involvement by angioimmunoblastic T-cell lymphoma from other reactive and malignant conditions (P-1216). Mod Pathol 2008;21(Suppl 1):266A.

20 Rodriguez-Pinilla SM, Atienza L, Murillo C, et al. Peripheral T-cell lymphoma with follicular T-cell markers. Am J Surg Pathol 2008;32:1787-1799.

21 Vinuesa CG, Tangye SG, Moser B, et al. Follicular B helper T cells in antibody responses and autoimmunity. Nat Rev Immunol 2005;5:853-865.

22 Rasheed A-U, Rahn H-P, Sallusto F, et al. Follicular B helper $\mathrm{T}$ cell activity is confined to CXCR5 ${ }^{\mathrm{hi}} \mathrm{ICOS}^{\mathrm{hi}}$ CD4 T cells and is independent of CD57 expression. Eur J Immunol 2006;36:1892-1903.
23 Sabattini E, Bisgaard K, Ascani S, et al. The EnVision ${ }^{+}$ system: a new immunohistochemical method for diagnostics and research. Critical comparison with the APAAP, ChemMate, CSA, LABC, and SABC techniques. J Clin Pathol 1998;51:506-511.

24 Kanavaros P, Lecs MC, Briere J, et al. Nasal T-cell lymphoma: a clinicopathological entity associated with peculiar phenotype and with Epstein-Barr virus. Blood 1993;81:2688-2695.

25 Bruggemann M, White H, Gaulard P, et al. Powerful strategy for polymerase chain reaction-based clonality assessment in T-cell malignancies. Report of the BIOMED-2 concerted Action BHM4CT98-3936. Leukemia 2007;21:215/221.

26 Attygalle AD, Chuang SS, Diss TC, et al. Distinguishing angioimmunoblastic T-cell lymphoma from peripheral T-cell lymphoma, unspecified, using morphology, immunophenotype and molecular genetics. Histopathology 2007;50:498-508.

27 Xerri L, Chetaille B, Seriari N, et al. Programmed death 1 is a marker of angioimmunoblastic T-cell lymphoma and B-cell small lymphocytic lymphoma/ chronic lymphocytic leukaemia. Hum Pathol 2008;39: 1050-1058.

28 Chandra P, Zhang X, Chiriboga L, et al. Angioimmunoblastic T-cell lymphoma: a tissue microarray analysis (P-1081). Mod Pathol 2007;87(Suppl 1):236A.

29 Hardie D, Johnson GD, Khan M, et al. Quantitative analysis of molecules which distinguish functional compartments within germinal centers. Eur J Immunol 1993;23:997-1004.

30 Zhou Y, Attygalle AD, Chuang SS, et al. Angioimmunoblastic T-cell lymphoma: histological progression associated with EBV and HHV6B viral load. Br J Haematol 2007;138:44-53.

31 Battegay M, Berger C, Rochlitz C, et al. EBV load correlating with clinical manifestation and treatment response in a patient with angioimmunoblastic T-cell lymphoma. Antivir Ther 602004;9:453-459.

32 de Leval L, Savilo E, Longtine J, et al. Peripheral T-cell Lymphoma with folicullar involvement and CD4+/ bcl-6+ phenotype. Am J Surg Pathol 2001;25:395-400.

33 Bacon CM, Paterson JC, Liu H, et al. Peripheral T-cell lymphoma with a follicular growth pattern: derivation from follicular $\mathrm{T}$ cells and relationship to angioimmunoblastic T-cell lymphoma. Br J Haematol 2008; 143:439-441.

34 Pileri SA, Weisenburger DD, Sng I, et al. Peripheral T-cell lymphoma, not otherwise specified. In: Swerdlow SH, Campo E, Harris NL et al. (eds). Pathology and Genetics of Tumours of Haematopoietic and Lymphoid tissues. World Health Organization Classification of Tumours, 4th edn. IARC press: Lyon, 2008, pp 306-308. 